\title{
BMJ Open Different predictors of pain severity across age and gender of a Chinese rural population: a cross-sectional survey
}

\author{
Xiao-kun Liu, ${ }^{1}$ Shui-yuan Xiao, ${ }^{1,2}$ Liang Zhou, ${ }^{3}$ Mi Hu, ${ }^{2}$ Hui-ming Liu $^{4}$
}

To cite: Liu X, Xiao S, Zhou L, et al. Different predictors of pain severity across age and gender of a Chinese rural population: a crosssectional survey. BMJ Open 2018;8:e020938. doi:10.1136/ bmjopen-2017-020938

- Prepublication history for this paper is available online. To view these files, please visit the journal online (http://dx.doi. org/10.1136/bmjopen-2017020938).

Received 6 December 2017 Revised 27 March 2018 Accepted 19 April 2018

Check for updates

${ }^{1}$ Mental Health Center, Xiangya Hospital, Central South University, Changsha, Hunan, China

${ }^{2}$ Department of Social Medicine and Health Management, School of Public Health, Central South University, Changsha, Hunan, China

${ }^{3}$ Affiliated Brain Hospital of Guangzhou Medical University (Guangzhou Huiai Hospital), Guangzhou, Guangdong, China ${ }^{4}$ Shenzhen Kangning Hospital, Shenzhen, Guangdong, China

Correspondence to

Dr Shui-yuan Xiao;

xiaosy@csu.edu.cn

\section{ABSTRACT}

Objectives To investigate a 4-week period of pain prevalence and the risk factors of experiencing pain among a rural Chinese population sample. To explore the psychosocial and health condition predictors of pain severity and the interactions of age and gender with these factors in real-life situations among the general adult population in China.

Methods Data were collected from a random multistage sample of 2052 participants (response rate $=95 \%$ ) in the rural areas of Liuyang, China. Visual analogue scale was used to assess participants' pain experienced and a series of internationally validated instruments to assess their sociodemographic characteristics, self-reported health status, depression symptoms, anxiety symptoms, sleep quality, self-efficacy and perceived stress.

Results The pain prevalence over the 4-week period in rural China was $66.18 \%$ (62.84\% for men and $68.82 \%$ for women). A logistic regression model revealed that being female (adjusted $\mathrm{OR}=1.58,95 \% \mathrm{Cl} 1.24$ to 2.02), age (adjusted $\mathrm{OR}=1.03,95 \% \mathrm{Cl} 1.02$ to 1.05), depressive symptoms (adjusted $\mathrm{OR}=1.07,95 \% \mathrm{Cl} 1.02$ to 1.13 ) and medium-quality sleep (adjusted $\mathrm{OR}=2.14,95 \% \mathrm{Cl} 1.26$ to 3.64) were significant risk factors for experiencing pain. General linear model analyses revealed that (1) pain severity of rural Chinese was related to self-rated physical health and social health; (2) the interactions of age, gender with employment status, depression symptoms, perceived stress and physical health were significant. Simple effect testing revealed that in different age groups, gender interacted with employment status, depression symptoms, perceived stress and physical health differently.

Conclusions Improving physical and social health could be effective in reducing the severity of pain and the treatment of pain should be designed specifically for different ages and genders among the general population.

\section{INTRODUCTION}

Pain is a public and clinical health concern. The annual prevalence of pain and chronic pain has been estimated to be $20 \%$ and $10 \%$ of the general population, respectively. ${ }^{12}$ To date, most studies on the prevalence of pain have been conducted in developed countries such as the USA, ${ }^{3-7}$ Canada, ${ }^{8-10}$ Australia, ${ }^{11-13}$ Britain $^{14}$ and European countries. ${ }^{15-18} \mathrm{~A}$ few studies on the prevalence of pain in the

\section{Strengths and limitations of this study}

This study established the 4-week prevalence of pain among a Chinese rural population.

- To the best of our knowledge, this is the first study reported which describes the psychosocial and health condition predictors on pain severity and the interactions of ages and genders in real-life situations among the general adult population.

- The cross-sectional design of this study prevented the causes of pain to be determined.

Chinese population have primarily focused on residents in the large cities. For example, Jackson et $a l^{19}$ reported that the prevalence of pain and chronic pain was $42.2 \%$ and $25.8 \%$, respectively, during a 6 -month study period of the residents in Chongqing, China. Chen et al studied Chinese from both urban and rural areas and found that the prevalence of chronic pain over the past 6 months among women and men in China was $39.92 \%$ and $32.17 \%$, respectively. ${ }^{20}$ The rural population in China comprises about half of China's total population and have significantly lower income ${ }^{21}$ and inferior medical health services $^{22} 23$ compared with the population living in urban areas. However, little is reported regarding the prevalence of pain experienced by the rural population in China.

Experiencing pain is a biopsychosocial process. ${ }^{1}$ The risk factors of experiencing pain throughout the general population include physiological and psychosocial factors. The physiological factors include genetics, injury and health status. The psychosocial factors include early life factors ${ }^{24}$ female in gender, ${ }^{20}{ }^{25}$ poor sleep, ${ }^{26-30}$ distressed mood (depression, anxiety), ${ }^{31}$ psychosocial environment (social suffering setting ${ }^{32}$ ), perceived stress, ${ }^{33}$ religion and self-efficacy (SE). ${ }^{34} 35$ The analysis of risk factors of pain among the rural 


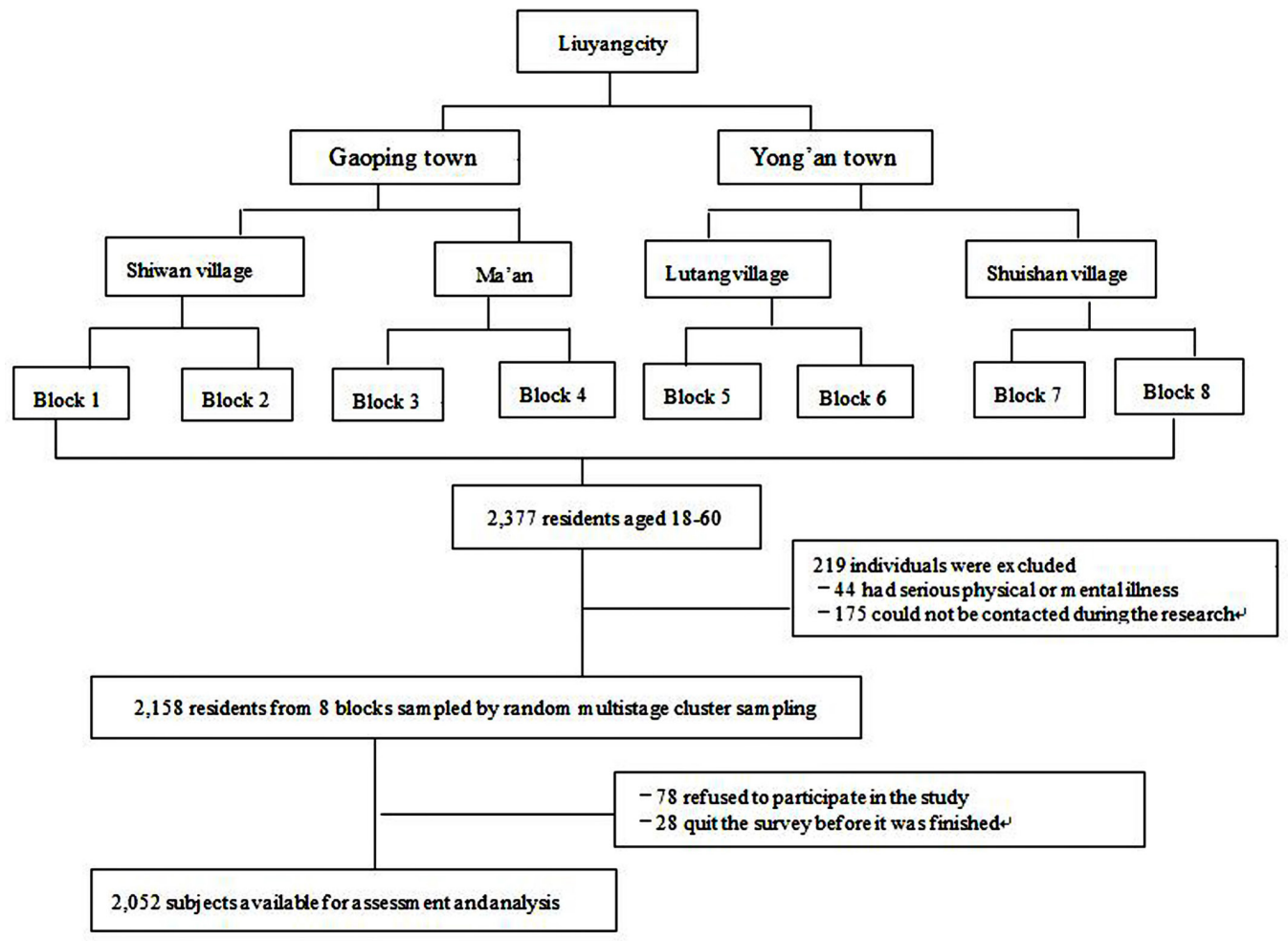

Figure 1 Recruitment and follow-up of study participants.

residents in China is required for target people who are at a greater risk and planning and facilitating treatment across rural areas in China.

The exploration of differences in pain experienced across age groups and gender has been recommended by the International Association for the Study of Pain. ${ }^{36}$ However, different predictors of pain severity across age groups and genders have received little attention. Most epidemiological and experimental studies have indicated that older people ${ }^{113738}$ and women ${ }^{39-41}$ are at greater risk of experiencing pain. However, the potentially different interactions of ages and genders with psychosocial status and health conditions on the severity of pain in real-life situation have not been adequately studied. To the best of our knowledge, few studies have been reported that consider the socioeconomic status (eg, employment vs unemployment) and mental health (such as depression symptoms, perceived stress) may interact differently across ages and genders, contributing to the severity of pain experienced.

This study reports a population-based survey across the rural areas of Liuyang City, Hunan province, China. The prevalence of pain among rural Chinese over a 4-week period was explored, and the risk factors of experiencing pain among this population were investigated. Further, the main effects and interactions of gender and age with psychosocial variables and three-dimensional health conditions on the severity of pain in real-life situation were explored. Significant differences of pain severity across ages and genders were hypothesised.

\section{METHODS}

Patient and public involvement

No specific kinds of patients were involved. All the participants were general adult population in the rural areas of Liuyang. The informed consent was interpreted to the rural participants by the local guide and the survey was conducted with their agreement of the informed consent orally. The participants agreed that results of this study will be published in the form of essays or articles, and no personal information will be disclosed in any report.

\section{Study design}

Liuyang is a representative rural city of the Hunan province, China, and classified as one of the national development and reform pilot cities. ${ }^{42}$ Liuyang County, located in the centre of Hunan province, has a total population of 1.4235 million including people of Han nationality and 34 ethnic minorities. Liuyang has industries in grain production, raising pigs and black goats, and is the centre of fireworks production in China, with a history of fireworks production greater than 1400 years. ${ }^{43}$ Administratively, Liuyang is divided into four districts in the urban areas and 33 towns in the rural areas. Rural towns in Liuyang are similar to each other in respect of geography, population sizes, gender and age distributions, social structure, public health and healthcare services, making residents in these rural towns comparable.

A cross-sectional survey of rural residents in Liuyang City was conducted from November 2010 to August 2011. As figure 1 showed, a three-stage stratified sample was used, consisting of (1) random sampling to select two 
Table 1 Sociodemographic characteristics of the sample $(n=2052)$

\begin{tabular}{|c|c|}
\hline Characteristics & n (\%) \\
\hline \multicolumn{2}{|l|}{ Gender } \\
\hline Male & $987(48.10)$ \\
\hline Female & $1065(51.90)$ \\
\hline \multicolumn{2}{|l|}{ Age (years) } \\
\hline $18-44$ & 796 (38.79) \\
\hline $45-59$ & $977(47.61)$ \\
\hline 60 and above & $279(13.60)$ \\
\hline \multicolumn{2}{|l|}{ Ethnicity } \\
\hline Han & 2042 (99.51) \\
\hline Non-Han & $10(0.49)$ \\
\hline \multicolumn{2}{|l|}{ Education } \\
\hline Illiterate & $47(2.30)$ \\
\hline Primary school or lower & $767(37.40)$ \\
\hline Middle school & $925(45.10)$ \\
\hline High school & $268(13.10)$ \\
\hline College or above & $45(2.20)$ \\
\hline \multicolumn{2}{|l|}{ Employment } \\
\hline Unemployed & $797(38.84)$ \\
\hline Employed & $1254(61.11)$ \\
\hline Agriculture & $891(43.42)$ \\
\hline Non-agriculture & $363(17.69)$ \\
\hline \multicolumn{2}{|l|}{ Annual income (person/ $¥)$} \\
\hline 1992 or less & $241(11.74)$ \\
\hline $1993-5523$ & $513(25)$ \\
\hline 5524 or greater & $1298(63.26)$ \\
\hline \multicolumn{2}{|l|}{ Marital status } \\
\hline Never married & $145(7.07)$ \\
\hline Married/cohabiting & 1867 (90.98) \\
\hline Divorced/separated/widowed & 40 (1.95) \\
\hline \multicolumn{2}{|l|}{ Religion } \\
\hline Yes & 205 (9.99) \\
\hline No & $1847(90.01)$ \\
\hline
\end{tabular}

towns from the 33 towns of Liuyang City according to the list of villages; (2) random sampling of two villages from each town; and (3) random sampling of two geographically natural blocks. Natural blocks were used to identify subjects. The target sample for this study comprised residents from eight geographically natural blocks. All adults in all households of the eight natural blocks were included in the final sample, with 2158 residents in total. The sample size is representative of the rural counties in Liuyang.

\section{Participants}

The current household registration system (known as the Hukou System) implemented in China divides the residents into agricultural and non-agricultural residencies and established a rural-urban division. ${ }^{44}$ A household registration record officially identifies a person as a resident to be rural or urban according to the inheritance and geographic location. Rural areas are less developed in many ways, compared with urban areas, such as infrastructure, education and healthcare.

The target population in this study was rural residents aged above 18 years who had lived in the Liuyang County for over 6 months. We excluded subjects (1) they could not be contacted after three attempts by the local investigators sent by the research team; or (2) had a serious physical or mental illness that influenced the experience of pain. A total of 2377 participants were initially included in the study, of whom 219 were excluded. Seventy-eight people $(2.8 \%)$ refused to participate, and $28(1.3 \%)$ dropped out of the survey before it was completed. Therefore, 2052 valid responses (response rate=95\%) were analysed.

\section{Quality control}

Interviewers included 12 graduates and three undergraduates from Central South University, all of whom underwent 2 days of centralised and unified training. The training included the content of the questionnaire, public health knowledge, and psychiatry and communication skills. All interviewers received this training so that they could administer the interview to the same standards.

\section{Procedure}

The investigation team visited each household and conducted face-to-face interviews. Each interview was comprised an initial interview and self-reported survey, and lasted approximately 1 hour for each participant. At the end of the survey, each participant received a thank you gift, such as a kitchen utensil. At the end of each day of interviews, a meeting was held to review the process, to check the quality of the questionnaires and to discuss any problems that had emerged during the interviews. All questionnaires were double-checked by two

\begin{tabular}{lcc}
\hline $\begin{array}{l}\text { Table } 2 \\
(\mathrm{n}=2052)\end{array}$ & Psychological characteristics of the participants \\
\hline Variable & Mean & SD \\
\hline Sleep quality & 7.28 & 2.55 \\
PHQ-9 & 3.64 & 3.92 \\
GAD-7 & 2.73 & 3.56 \\
Health status & & \\
$\quad$ Physical health & 142.58 & 18.68 \\
$\quad$ Mental health & 117.17 & 21.44 \\
$\quad$ Social health & 85.12 & 18.76 \\
Self-efficacy & 27.09 & 4.36 \\
Perceived stress & 18.33 & 6.47 \\
\hline
\end{tabular}

GAD-7, 7-item Generalized Anxiety Disorder scale; PHQ-9, Patient Health Questionnaire Depression Module. 
Table 3 Pain prevalence over the past 4 weeks according to different ages

\begin{tabular}{|c|c|c|c|c|c|c|}
\hline \multirow[b]{2}{*}{ Age } & \multirow[b]{2}{*}{ Gender } & \multirow[b]{2}{*}{ Pain free } & \multirow{2}{*}{$\begin{array}{l}\text { Experienced } \\
\text { pain }\end{array}$} & \multirow{2}{*}{$\begin{array}{l}\text { 4-week prevalence } \\
\text { rate }\end{array}$} & \multicolumn{2}{|c|}{ Pain severity } \\
\hline & & & & & Mean & SD \\
\hline \multirow{3}{*}{$\begin{array}{l}18-44 \\
(n=796)\end{array}$} & Male & 157 & 170 & 51.99 & 5.08 & 2.70 \\
\hline & Female & 182 & 287 & 61.19 & 4.51 & 2.46 \\
\hline & Sum & 339 & 457 & 57.41 & 4.72 & 2.57 \\
\hline \multirow{3}{*}{$\begin{array}{l}45-59 \\
(n=977)\end{array}$} & Male & 147 & 318 & 68.39 & 5.06 & 2.33 \\
\hline & Female & 155 & 357 & 69.73 & 4.99 & 2.37 \\
\hline & Sum & 302 & 675 & 69.09 & 5.02 & 2.35 \\
\hline \multirow{3}{*}{$\begin{array}{l}60 \text { and above } \\
(n=279)\end{array}$} & Male & 33 & 82 & 71.30 & 5.29 & 2.53 \\
\hline & Female & 20 & 144 & 87.80 & 5.00 & 2.60 \\
\hline & Sum & 53 & 226 & 81.00 & 5.11 & 2.57 \\
\hline \multirow[t]{2}{*}{ All ages } & Male & 337 & 570 & 62.84 & 5.10 & 2.47 \\
\hline & Female & 357 & 788 & 68.82 & 4.82 & 2.45 \\
\hline $\mathrm{n}=2052$ & Total & 694 & 1358 & 66.18 & 4.94 & 2.47 \\
\hline
\end{tabular}

quality control specialists to ensure that there were no inconsistencies, missing items or errors, and then handed to one quality control specialist for a final check.

\section{The survey}

Initial interview

A short interview conducted for approximately $15 \mathrm{~min}$ consisted of the two parts:

\section{Sociodemographic status}

The participant was interviewed about his/her gender, age, highest level of education completed, employment status (unemployment denoted with 1, employment with 2), income and religion. Education was divided into 1 =primary school or lower, $2=$ middle school,

\begin{tabular}{lcllll}
\hline \multicolumn{7}{l}{ Table 4} & \multicolumn{6}{l}{ Risk factors of experiencing pain } \\
\hline Variables & OR & aOR & aOR $(95 \%$ Cl) & P values \\
\hline Gender & 1.31 & 1.58 & 1.24 & 2.02 & 0.00 \\
\hline Age & 1.03 & 1.03 & 1.02 & 1.05 & 0.00 \\
\hline Education & 0.77 & 1.14 & 0.95 & 1.37 & 0.15 \\
\hline Employment condition & 0.87 & 1.26 & 0.98 & 1.62 & 0.08 \\
\hline Annual income & 1.00 & 1.00 & 1.00 & 1.00 & 0.65 \\
\hline Religion & 0.59 & 0.93 & 0.62 & 1.38 & 0.71 \\
\hline Physical health & 0.92 & 0.92 & 0.90 & 0.93 & 0.00 \\
\hline Mental health & 0.96 & 0.99 & 0.99 & 1.00 & 0.16 \\
\hline Social health & 0.98 & 1.01 & 1.00 & 1.01 & 0.08 \\
\hline Depressive symptoms & 1.21 & 1.07 & 1.02 & 1.13 & 0.01 \\
\hline Anxiety symptoms & 1.18 & 0.99 & 0.94 & 1.05 & 0.77 \\
\hline Self-efficacy & 1.02 & 1.02 & 0.99 & 1.04 & 0.28 \\
\hline Perceived stress & 1.06 & 0.99 & 0.97 & 1.02 & 0.56 \\
\hline Sleep quality & & & & & \\
\hline Poor-quality sleep & 4.04 & 1.49 & 0.87 & 2.53 & 0.15 \\
\hline Medium-quality sleep & 2.25 & 2.14 & 1.26 & 3.64 & 0.01 \\
\hline
\end{tabular}

aOR, adjusted OR; OR, crude OR. 3=high school and above. Employment was divided into two categories: employed and unemployed. Income was measured annually. Religion was defined as $1=$ religious, $2=$ non-religious.

\section{Pain}

Participants were asked by the interviewer whether they had experienced an episode of pain within the past 4 weeks (yes/no). If they were pain free, the interviewer recorded ' 0 '. If they had experienced pain, their pain intensity over the past 4 weeks was assessed using a visual analogue scale (VAS), with ratings from 0 (no pain at all) to 10 (the worst pain imaginable) along a straight line. The VAS is a widely used measurement for the severity of pain and subjective experience ${ }^{4546}$ and its reliability and validity have been tested and verified. ${ }^{47-49}$ The participant recalled the mean level of their pain severity during the past 4 weeks and selected the level that could best represent his/her pain severity on VAS. It has been reported in the literature that when recalled over a period of 1 or 4 weeks, the outcome was well correlated with daily momentary assessments. ${ }^{50-52}$ Long-term recall is significantly influenced by recall bias. ${ }^{53} 54$ Therefore, the participants were not asked to recall the severity of pain over a 4-week period. The recollection of pain across a 4-week period is an indicator of acute pain, which indicates the demands of public health concern and clinical health treatment.

\section{Self-administrated assessment}

After the interview, each participant filled out the following questionnaires.

\section{Perceived health status}

The Self-Rated Health Measurement Scale (SRHMS), developed and revised by $\mathrm{Xu}$ et $a l^{55}$ includes 48 items, and has a Cronbach's $\alpha$ coefficient of $0.93 .^{56}$ The SRHMS assesses three dimensions of health: physical, mental and social. Physical health indicates one's physical function. 
Table 5 Tests of between-subjects effects

\begin{tabular}{|c|c|c|c|c|c|}
\hline Source & $\begin{array}{l}\text { Type III sum of } \\
\text { squares }\end{array}$ & df & Mean square & $\mathbf{F}$ & Significance \\
\hline Corrected model & 2451.13 & 117 & 20.95 & 4.57 & 0.00 \\
\hline Intercept & 772.01 & 1 & 772.01 & 168.31 & 0.00 \\
\hline Gender & 7.87 & 1 & 7.87 & 1.72 & 0.19 \\
\hline Age & 14.79 & 2 & 7.40 & 1.61 & 0.20 \\
\hline Education & 0.49 & 2 & 0.24 & 0.05 & 0.95 \\
\hline Employment & 3.56 & 1 & 3.56 & 0.78 & 0.38 \\
\hline Annual income & 10.29 & 2 & 5.15 & 1.12 & 0.33 \\
\hline Religion & 2.14 & 1 & 2.14 & 0.47 & 0.49 \\
\hline Depression & 8.99 & 3 & 3.00 & 0.65 & 0.58 \\
\hline Anxiety & 3.90 & 3 & 1.30 & 0.28 & 0.84 \\
\hline Sleep & 14.44 & 2 & 7.22 & 1.57 & 0.21 \\
\hline P-health & 684.25 & 1 & 684.25 & 149.18 & 0.00 \\
\hline M-health & 14.54 & 1 & 14.54 & 3.17 & 0.08 \\
\hline S-health & 31.94 & 1 & 31.94 & 6.96 & 0.01 \\
\hline Stress & 0.01 & 1 & 0.01 & 0.00 & 0.97 \\
\hline SE & 3.07 & 1 & 3.07 & 0.67 & 0.42 \\
\hline Age $^{*}$ gender education & 36.39 & 10 & 3.64 & 0.80 & 0.64 \\
\hline Age $^{\star}$ gender employment & 53.72 & 5 & 10.75 & 2.34 & 0.04 \\
\hline Age $^{\star}$ gender ${ }^{\star}$ income & 63.99 & 10 & 6.40 & 1.40 & 0.18 \\
\hline Age $^{\star}$ gender ${ }^{\star}$ religion & 1.65 & 5 & 0.33 & 0.07 & 0.99 \\
\hline Age $^{\star}$ gender ${ }^{\star}$ depression & 131.14 & 14 & 9.37 & 2.04 & 0.01 \\
\hline 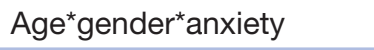 & 53.80 & 14 & 3.84 & 0.84 & 0.63 \\
\hline Age ${ }^{*}$ gender*sleep & 37.94 & 10 & 3.79 & 0.83 & 0.60 \\
\hline Age ${ }^{*}$ gender*P-health & 65.66 & 5 & 13.13 & 2.86 & 0.01 \\
\hline Age ${ }^{*}$ gender ${ }^{*} M$-health & 44.62 & 5 & 8.92 & 1.95 & 0.08 \\
\hline Age ${ }^{*}$ gender ${ }^{*}$ S-health & 10.06 & 5 & 2.01 & 0.44 & 0.82 \\
\hline Age ${ }^{*}$ gender*stress & 52.68 & 5 & 10.54 & 2.30 & 0.04 \\
\hline Age $^{*}$ gender*SE & 22.68 & 5 & 4.54 & 0.98 & 0.42 \\
\hline
\end{tabular}

income, annual income; M-health, mental health; P-health, physical health; S-health, social health; SE, self-efficacy.

Mental health denotes emotional and cognitive health. Social health refers to social relationships and social networks, such as the level of communication between family members or the availability of a support network during times of need. The highest possible scores for physical, mental and social health are 170, 150 and 120, respectively, and a maximum overall score of $4400^{57}$ The higher the score obtained by a participant, the better his or her health was concluded to be. The SRHMS is not a diagnostic instrument, and there are no cut-points for delineating the different levels of health conditions.

\section{Psychological variables}

Depression symptoms were assessed using the Patient Health Questionnaire Depression Module (PHQ-9), a 9-item scale, with each item based on the criteria for depressive disorders listed in the Diagnostic and Statistical Manual of Mental Disorders (DSM-V) ${ }^{58}{ }^{59}$ Each item is rated on a scale from 0 ('not at all') to 3 ('nearly every day') ${ }^{60}$ and the total score ranges from 0 to 27 . The Chinese version of the PHQ-9 has a Cronbach's $\alpha$ of $0.86 .^{61}$ The results of the PHQ-9 may be used for the screening of depression severity with the scores of $0-4,5-9,10-14,15-19$ and 20-27, indicating none-minimal, slight, moderate, moderately severe and severe depression according to DSM-IV.

Anxious symptoms were assessed using the Generalized Anxiety Disorder scale (GAD), a 7-item scale developed by Spitzer et al..$^{62}$ Each item is rated on a scale from 0 ('not at all') to 3 ('nearly every day'). ${ }^{62}$ The scale was found to have excellent internal consistency, with a Cronbach's $\alpha$ coefficient of $0.92 .{ }^{62}$ The GAD-7 has been used widely and well validated in general populations ${ }^{63}$ as well as psychiatric settings. ${ }^{64}$ Scores of $0-4,5-9,10-14$ and $\geq 15$ indicate none, slight, moderate and severe anxiety symptoms according to DSM-IV. 


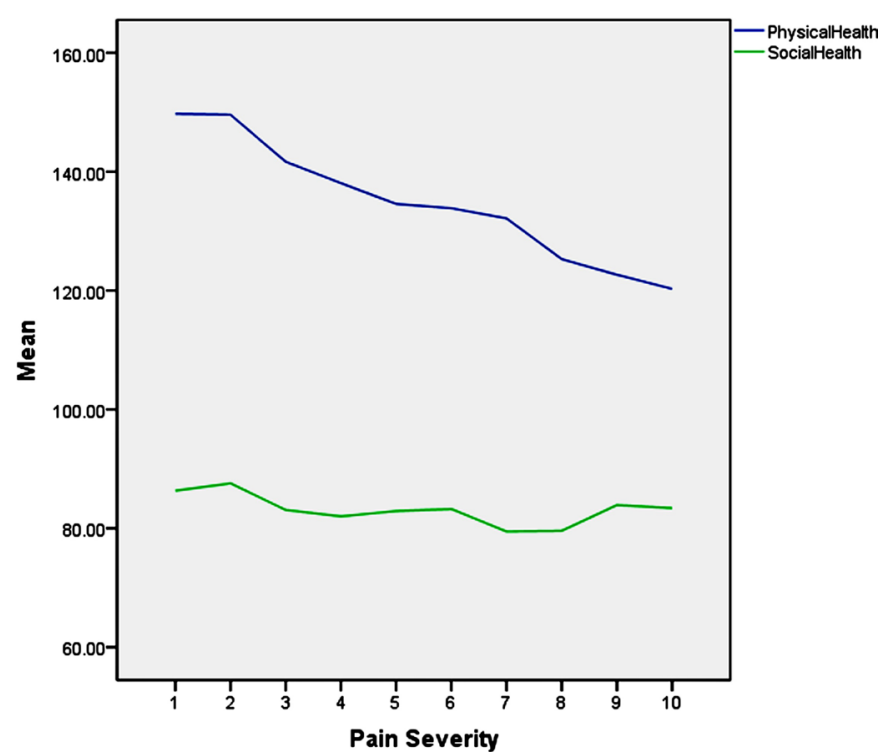

Figure 2 The relationship between physical, social health and pain severity.

Global sleep quality was assessed by the VAS. The participant selected the point along a $10 \mathrm{~cm}$ horizontal line that best represented his/her overall sleep quality with ' 0 ' (indicating the worst sleep quality) and ' 10 ' (indicating the best sleep quality). The distance is measured from the left edge to the participant's mark to reflect the subjective quality of sleep. We divided sleep quality into three categories based on the ratings: 0-3.33 defined as group 1 (poor sleep quality); 3.34-6.67 defined as group 2 (medium sleep quality); 6.68-10 (high sleep quality) defined as group 3 .

SE was assessed using the General Self-Efficacy Scale (GSES), originally developed in German by Schwarzer and Jerusalem in 1979 and has been confirmed validated in multicultural settings. ${ }^{6566}$ The scale consists of 10 statements, and the Cronbach's $\alpha$ coefficient of the Chinese GSES was found to be between 0.89 and $0.92 .{ }^{67}$

Perceived stress was assessed using the Chinese edition of the Perceived Stress Scale (CPSS). Cohen et al developed the Perceived Stress Scale (PSS) as a stress measure. ${ }^{68}$ Originally, this self-reported scale comprised 14 items. A shortened 10-item version (PSS-10) is reported which is psychometrically superior to the original 14-item version, as it had higher validity and internal reliability compared with the PSS- $14{ }^{69}$ The CPSS-10 was found to have a stable two-factor structure of satisfactory internal consistency

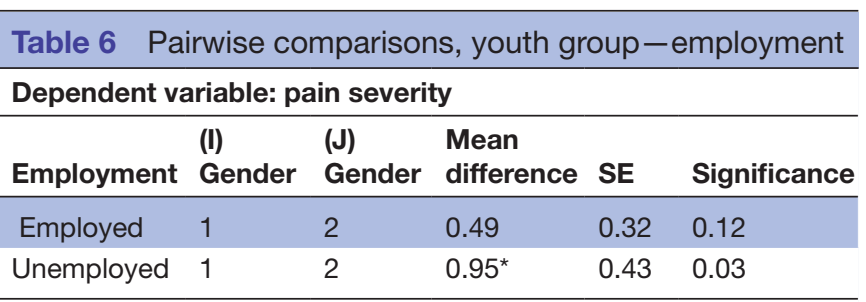

Based on estimated marginal means.

Note: simple effect analysis of gender and employment of youth group.

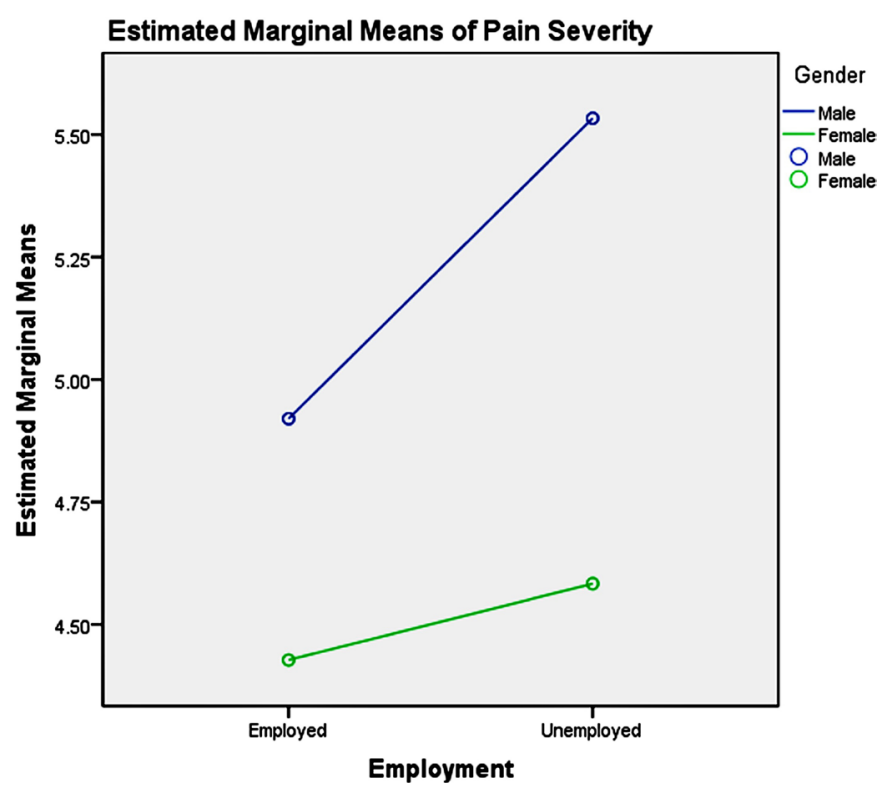

Figure 3 Gender-employment effects on pain severity in youth.

and construct validity, with a Cronbach's $\alpha$ coefficient of $0.70 .{ }^{70}$ Each item of the CPSS was rated on a 5-point scale, ranging from 1 to 5 . The total scores of the CPSS were calculated by adding four reverse items and another six items. The possible total scores ranged from 10 to 50 (higher score indicating greater stress). There are no cut-points of the CPSS that indicate different levels of perceived stress.

\section{Statistical analysis}

Sample characteristics were described using basic descriptive statistics. Logistic regression analysis was used to identify the risk factors of experiencing pain. The dependent variable was experiencing pain versus being pain free. $P$ values smaller than 0.05 were considered significant. Analyses were performed using SPSS V.18.0. Independent variables included: (1) sociodemographic variables, gender, age, income, degree of education, religious belief and employment status; (2) health condition status: physical, mental and social health; (3) psychological variables: PHQ-9 score, GAD-7 score, SE, perceived stress and sleep quality. Logistic regression was used to explore the factors

Table 7 Pairwise comparisons, youth group-depression

\begin{tabular}{|c|c|c|c|c|c|}
\hline \multicolumn{6}{|c|}{ Dependent variable: pain severity } \\
\hline Depression & $\begin{array}{l}\text { (I) } \\
\text { Gender }\end{array}$ & $\begin{array}{l}\text { (J) } \\
\text { Gender }\end{array}$ & $\begin{array}{l}\text { Mean } \\
\text { difference }\end{array}$ & SE & Significance \\
\hline Severe & 1 & 2 & 0.21 & 1.56 & 0.89 \\
\hline Moderate & 1 & 2 & 0.31 & 0.77 & 0.69 \\
\hline Slight & 1 & 2 & -0.36 & 0.42 & 0.43 \\
\hline None & 1 & 2 & $1.21^{*}$ & 0.32 & 0.00 \\
\hline
\end{tabular}

Based on estimated marginal means.

Note: simple effect analysis of gender and depression symptoms of youth group. 


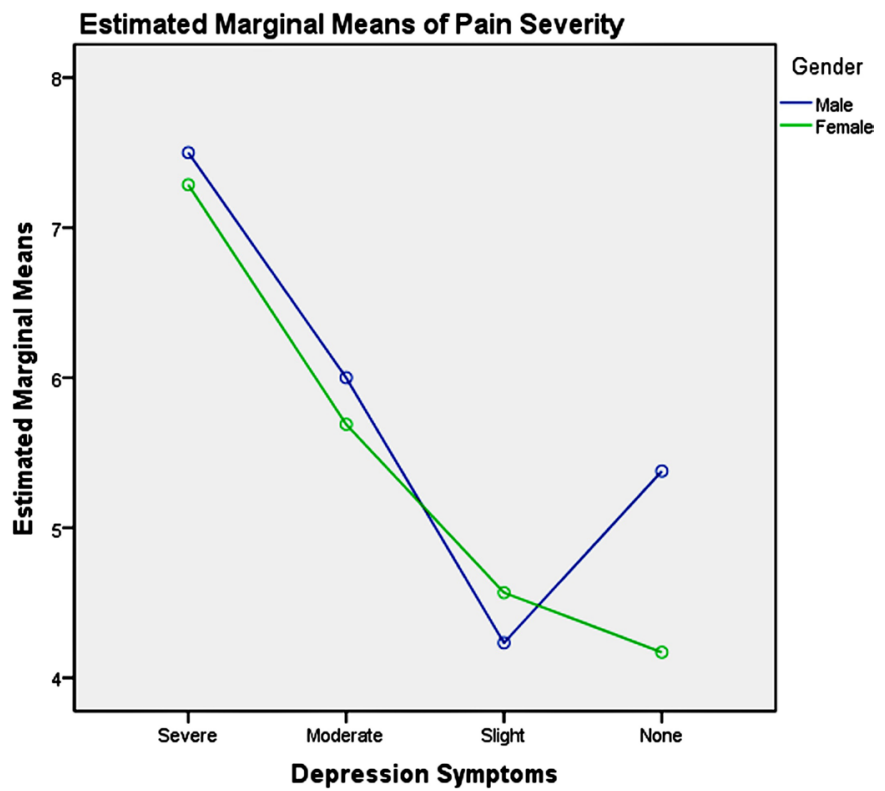

Figure 4 Gender and depression symptom effects on pain severity in youth.

related to experiencing pain. Sleep quality was set as the category variable.

A general linear model was used to explore the main effects and interactions of age and gender with other predictors on the severity of pain. The dependent variable was pain severity $(y=1-10)$. The independent variables were the same as those in the logistic regression model. Any interactions found between age, gender and another predictor were further studied using simple effect tests. Age was divided into three groups (youth, middle aged and elderly). In each age group, the interactions between gender and other predictors were tested using pairwise comparisons.

\section{RESULTS}

\section{Sample characteristics}

A total of 2052 participants (987 male, 1065 female) completed the interview process, with an overall response rate of $95.09 \%$. The demographic characteristics of the sample are shown in table 1 . There were more female $(51.90 \%)$ participants than male participants $(48.10 \%)$. In terms of age groups, $38.79 \%$ were young, $47.61 \%$ were middle aged and $13.60 \%$ were elderly. Most of the sample was of Han ethnicity $(99.51 \%)$, married $(90.98 \%)$ and

\begin{tabular}{|c|c|c|c|c|c|}
\hline \multicolumn{6}{|c|}{ Dependent variable: pain severity } \\
\hline P-health & $\begin{array}{l}\text { (I) } \\
\text { Gender }\end{array}$ & $\begin{array}{l}\text { (J) } \\
\text { Gender }\end{array}$ & $\begin{array}{l}\text { Mean } \\
\text { difference }\end{array}$ & SE & Significance \\
\hline $57-113$ & 1 & 2 & -0.49 & 1.07 & 0.65 \\
\hline $114-170$ & 1 & 2 & $0.61^{*}$ & 0.25 & 0.02 \\
\hline
\end{tabular}

Based on estimated marginal means.

Note: simple effect analysis of gender and physical health of youth group.

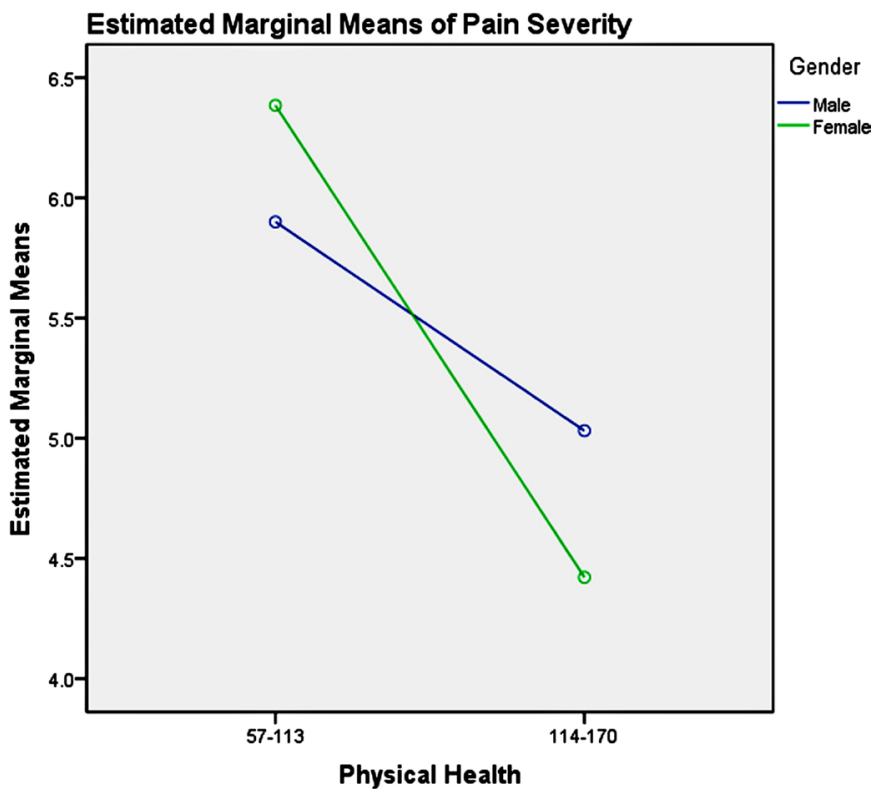

Figure 5 Gender and physical health effects on pain severity in youth.

non-religious $(90.01 \%)$, while $90.9 \%$ was married/cohabiting; $84.75 \%$ of the sample was of low education (middle school and below) and $61.11 \%$ was employed full-time (43.42\% employed in agriculture, $17.69 \%$ in non-agriculture). In 2009, the national rural poverty line was defined as below $¥ 1992 /$ year. In the Hunan province in 2010, the average income per farmer was $¥ 5523 /$ year. Income level was divided into three groups: low (¥1992/year or less), medium (¥1993-¥5523/year) and high (above ¥5524/ year). A total of 241 participants $(0.25 \%)$ were below the poverty level, 513 participants $(25 \%)$ had medium income and $1298(63.26 \%)$ had high income.

The psychological characteristics of the 2052 participants are presented in table 2. The participants' mean score of sleep quality was $7.28 \pm 2.55$. Their mean score for depression symptoms was $3.64 \pm 3.92$, and a mean score of anxiety symptoms was $2.73 \pm 3.56$. The mean \pm SD scores for physical, mental and social health were $142.58 \pm 18.68$, $117.17 \pm 21.44$ and $85.12 \pm 18.76$, respectively. The mean scores for SE and perceived stress were $27.09 \pm 4.36$ and $18.33 \pm 6.47$, respectively.

Table 9 Pairwise comparisons, youth group-perceived stress

\begin{tabular}{|c|c|c|c|c|c|}
\hline \multicolumn{6}{|c|}{ Dependent variable: pain severity } \\
\hline $\begin{array}{l}\text { Perceived } \\
\text { stress }\end{array}$ & $\begin{array}{l}\text { (I) } \\
\text { Gender }\end{array}$ & $\begin{array}{l}\text { (J) } \\
\text { Gender }\end{array}$ & $\begin{array}{l}\text { Mean } \\
\text { difference }\end{array}$ & SE & Significance \\
\hline $10-22$ & 1 & 2 & 0.35 & 0.42 & 0.40 \\
\hline $23-37$ & 1 & 2 & $0.67^{*}$ & 0.31 & 0.03 \\
\hline $38-50$ & 1 & 2 & $\dagger$ & - & - \\
\hline
\end{tabular}

Based on estimated marginal means.

†The level combination of factors in (I) is not observed.

Note: simple effect analysis of gender and perceived stress of youth group. 


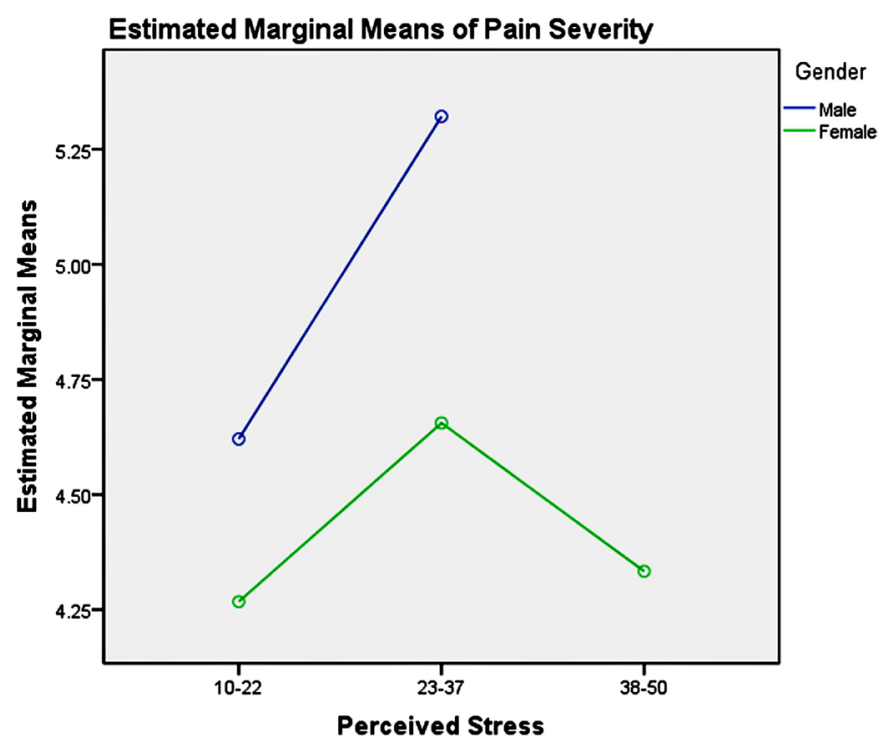

Figure 6 Gender and perceived stress effects on pain severity in youth.

\section{Pain prevalence over the past 4 weeks in rural China}

As the table 3 illustrated, the prevalence of experiencing pain across the 4 -week period was $66.18 \%$ overall, $62.84 \%$ for men and $68.82 \%$ for women. The prevalence peaked at $81.00 \%$ in the oldest age group (60 years and above) with $71.30 \%$ for men and $87.80 \%$ for women. The average pain severity for men was 5.10, with an SD of 2.47. The average pain severity for women was 4.82 , with an SD of 2.45. The oldest groups of both genders had the most intense pain severity.

\section{Risk factors for experiencing pain}

The independent variable was pain free versus experiencing pain. The dependent variables include: health status (physical, mental and social health); sociodemographic cofounders and psychological cofounders. Crude ORs and adjusted ORs for experiencing pain were calculated. Sleep has been divided into a categorical variable, included as a dummy variable, and highquality sleep was set as the reference group. As shown in table 4, gender (adjusted $\mathrm{OR}=1.58,95 \%$ CI 1.24 to 2.02), age (adjusted $\mathrm{OR}=1.03,95 \%$ CI 1.02 to 1.05 ), depressive symptoms (adjusted OR=1.07, 95\% CI 1.02 to 1.13 ) and medium-quality sleep (adjusted OR=2.14, 95\% CI 1.26 to 3.64) were significant risk factors for experiencing pain.

\begin{tabular}{|c|c|c|c|c|c|}
\hline \multicolumn{6}{|c|}{ Dependent variable: pain severity } \\
\hline Employment & $\begin{array}{l}\text { (I) } \\
\text { Gender }\end{array}$ & $\begin{array}{l}\text { (J) } \\
\text { Gender }\end{array}$ & $\begin{array}{l}\text { Mean } \\
\text { difference }\end{array}$ & SE & Significance \\
\hline Employed & 1 & 2 & -0.19 & 0.23 & 0.39 \\
\hline Unemployed & 1 & 2 & $1.32^{*}$ & 0.37 & 0.00 \\
\hline
\end{tabular}

Based on estimated marginal means.

Note: simple effect analysis of gender and employment of middleaged group.
Estimated Marginal Means of Pain Severity

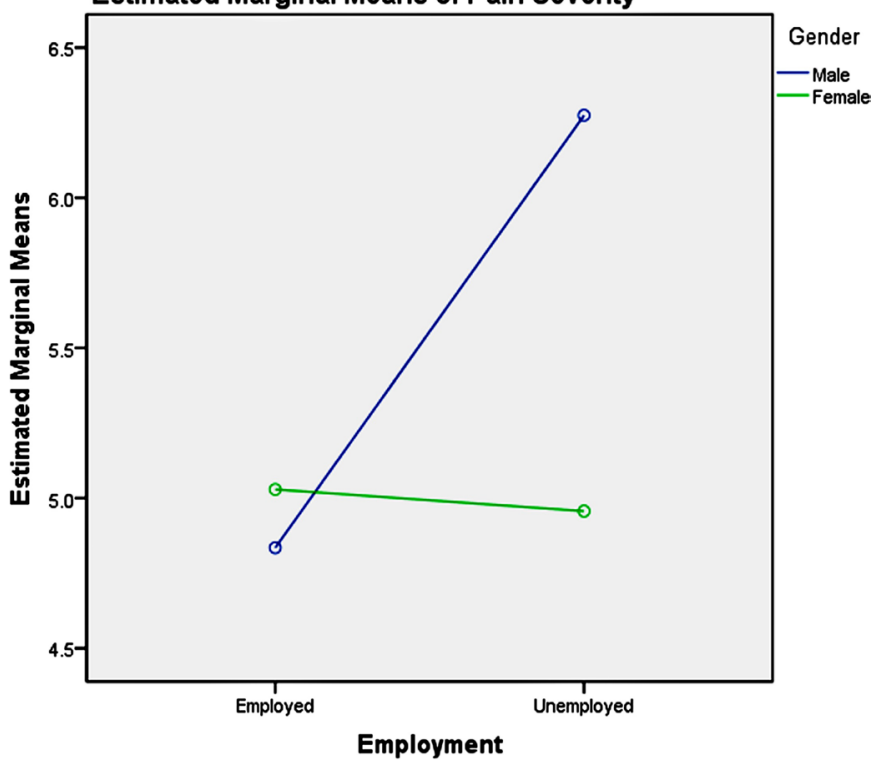

Figure 7 Gender-employment effects on pain severity in the middle aged.

Physical health (adjusted OR=0.92, 95\% CI 0.90 to 0.93 ) was a protective factor against experiencing pain.

\section{Predictors of pain severity across different age groups and genders}

A general linear model was used to explore the main effects and interactions of age and gender with other predictors on the severity of pain. The dependent variable was pain intensity. The independent variables were the same as those used in the above logistic models. The results suggest that physical health and social health significantly influenced pain severity (table 5), while age, gender with employment status, depression symptoms, physical health and perceived stress interacted significantly. As figure 2 showed, physical health and social health related with pain severity negatively in the overall condition.

The three-factor interactions present were age*gender*employment, age*gender*depression, age*gender*p-health and age*gender*stress. The age was split into three groups and the simple effects of gender within each significant interaction of the other variables were

Table 11 Pairwise comparisons, middle-aged groupdepression

\begin{tabular}{|c|c|c|c|c|c|}
\hline \multicolumn{6}{|c|}{ Dependent variable: pain severity } \\
\hline Depression & $\begin{array}{l}\text { (I) } \\
\text { Gender }\end{array}$ & $\begin{array}{l}\text { (J) } \\
\text { Gender }\end{array}$ & $\begin{array}{l}\text { Mean } \\
\text { difference }\end{array}$ & SE & Significance \\
\hline Severe & 1 & 2 & $-2.52^{*}$ & 1.06 & 0.02 \\
\hline Moderate & 1 & 2 & 0.55 & 0.62 & 0.38 \\
\hline Slight & 1 & 2 & -0.37 & 0.36 & 0.30 \\
\hline None & 1 & 2 & 0.14 & 0.22 & 0.53 \\
\hline
\end{tabular}

Based on estimated marginal means

Note: simple effect analysis of gender and depression symptoms of middle-aged group. 
Estimated Marginal Means of Pain Severity

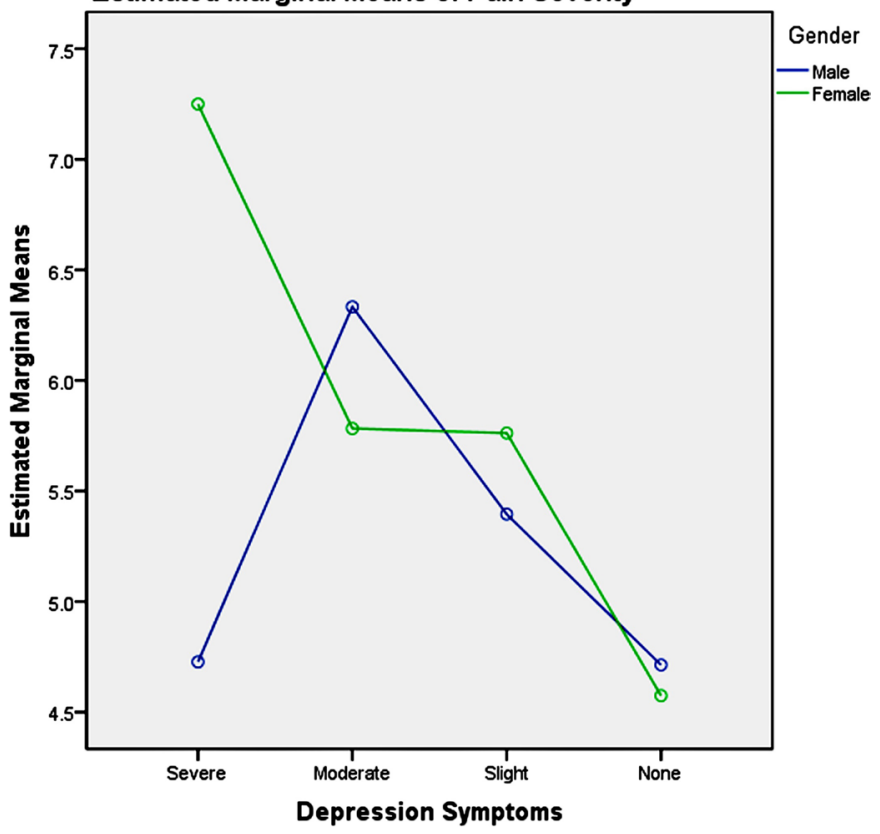

Figure 8 Gender and depression symptom effects on pain severity in the middle aged.

explored in each age group. These tests are based on the estimable independent, linear pairwise comparisons between the estimated marginal means.

The divisions of age groups were made according to the WHO report from World Health Day 2012: Ageing and Health. ${ }^{71}$ Participants were divided into three groups: youth group (18-44 years old), middle-aged group (45-59 years old) and elderly group (60 and above years old). Depression symptoms were coded from $\mathrm{y}=1-4$, based on moderate and above moderately severe, mild, slight and no depression symptoms. Anxiety symptoms were divided into $y=1-4$, based on moderate and above severe, mild, slight and no anxiety severity. Physical health was divided into three categories based on the scores: (1) scores of 0-56 were defined as 1 denoting poor physical health; (2) scores of 57-113 were defined as 2 denoting average physical health; (3) scores of 114-160 were defined as 3 denoting good physical health. Perceived stress was divided into three groups and scores of 10-22 represented

$\begin{aligned} & \text { Table } 12 \\
& \text { health }\end{aligned}$
\begin{tabular}{rlllll}
\multicolumn{7}{l}{ Pairwise comparisons, middle-aged group-P- } \\
\hline Dependent variable: pain severity \\
P-health & Gender & $\begin{array}{l}\text { (J) Gender } \\
\text { (I) }\end{array}$ & $\begin{array}{l}\text { Mean } \\
\text { difference }\end{array}$ & SE & Significance \\
\hline $0-56$ & 1 & 2 & $*$ & - & - \\
$57-113$ & 1 & 2 & -1.02 & 0.60 & 0.09 \\
$114-170$ & 1 & 2 & 0.07 & 0.18 & 0.71 \\
\hline
\end{tabular}

Based on estimated marginal means.

*The level combination of factors in (I) is not observed.

Note: simple effect analysis of gender and physical health of middleaged group.
Estimated Marginal Means of Pain Severity

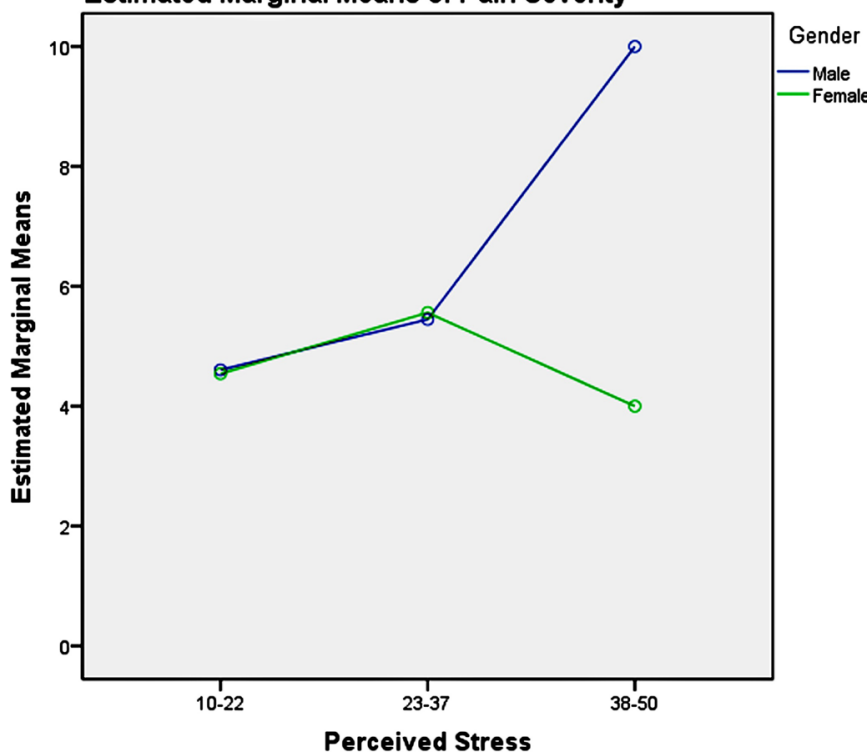

Figure 9 Gender and perceived stress effects on pain severity in the middle aged.

lower stress, scores of 23-37 represented average stress and scores of 38-50 represented high stress.

Among the youth group, pairwise comparisons revealed: (1) unemployment influenced men and women differently, as shown in table 6 and figure 3, which increased men's pain intensity significantly; (2) the absence of depression could significantly decrease the pain severity in the young women, compared with men, as presented in table 7 and figure 4; (3) good physical health influenced women's pain severity negatively, greater effect than that seen in men's, which is shown in table 8 and figure 5; (4) average level stress increased young men's pain intensity more dramatically than in women's as shown in table 9 and figure 6.

Among the middle-aged group, pairwise comparisons revealed: (1) unemployment influenced men and women differently, as table 10 and figure 7 showed, which significantly increased men's pain severity; (2) severe depression symptoms could significantly increase the pain severity of the mid-aged women, compared with the men as shown in table 11 and figure 8; (3) the influence of physical health on gender in the middle-aged group was not significant as illustrated in table 12; (4) high stress could significantly

Table 13 Pairwise comparisons, middle aged groupperceived stress

\begin{tabular}{llllll}
\hline \multicolumn{7}{l}{ Dependent variable: pain severity } \\
\hline $\begin{array}{l}\text { Perceived } \\
\text { stress }\end{array}$ & $\begin{array}{l}\text { (I) } \\
\text { Gender }\end{array}$ & $\begin{array}{l}\text { G) } \\
\text { Gender }\end{array}$ & $\begin{array}{l}\text { Mean } \\
\text { difference }\end{array}$ & SE & Significance \\
\hline $10-22$ & 1 & 2 & 0.06 & 0.25 & 0.79 \\
$23-37$ & 1 & 2 & -0.11 & 0.26 & 0.66 \\
$38-50$ & 1 & 2 & $6.00^{*}$ & 2.29 & 0.01 \\
\hline
\end{tabular}

Based on estimated marginal means. 
Table 14 Pairwise comparisons, elderly groupemployment

\begin{tabular}{|c|c|c|c|c|c|}
\hline \multicolumn{6}{|c|}{ Dependent variable: pain severity } \\
\hline Employment & $\begin{array}{l}\text { (I) } \\
\text { Gender }\end{array}$ & $\begin{array}{l}\text { (J) } \\
\text { Gender }\end{array}$ & $\begin{array}{l}\text { Mean } \\
\text { difference }\end{array}$ & SE & Significance \\
\hline Employed & 1 & 2 & -0.35 & 0.47 & 0.46 \\
\hline Unemployed & 1 & 2 & $1.66^{*}$ & 0.65 & 0.01 \\
\hline
\end{tabular}

Based on estimated marginal means.

Note: simple effect analysis of gender and employment of elderly group.

increase middle-aged men's pain severity, compared with that in women's, which is shown in table 13 and figure 9.

Among the elderly group, pairwise comparisons revealed that unemployment influenced men and women differently, as shown in table 14 and figure 10, which significantly increased men's pain severity. The influence of depression symptoms, physical health and perceived stress on gender in the elderly group was not significant, which was shown in tables $15-17$, respectively.

\section{DISCUSSION}

\section{Pain prevalence in rural China}

This study indicates that the pain prevalence among rural Chinese over a 4 -week period was to be $66.18 \%$, or $62.84 \%$ for men and $68.82 \%$ for women. The prevalence for both genders peaked in the oldest group (60 years and above). The pain prevalence of rural Chinese appeared to be higher than that previously reported for urban Chinese population, ${ }^{19} 20$ and higher than the pain prevalence of adults in the USA, ${ }^{7}$ Canada ${ }^{8}$ and Britain. ${ }^{14}$ However, the cited studies examined chronic pain (pain lasting $\geq 3$ months) and could produce substantially lower prevalence rates compared with pain over a 4-week period.

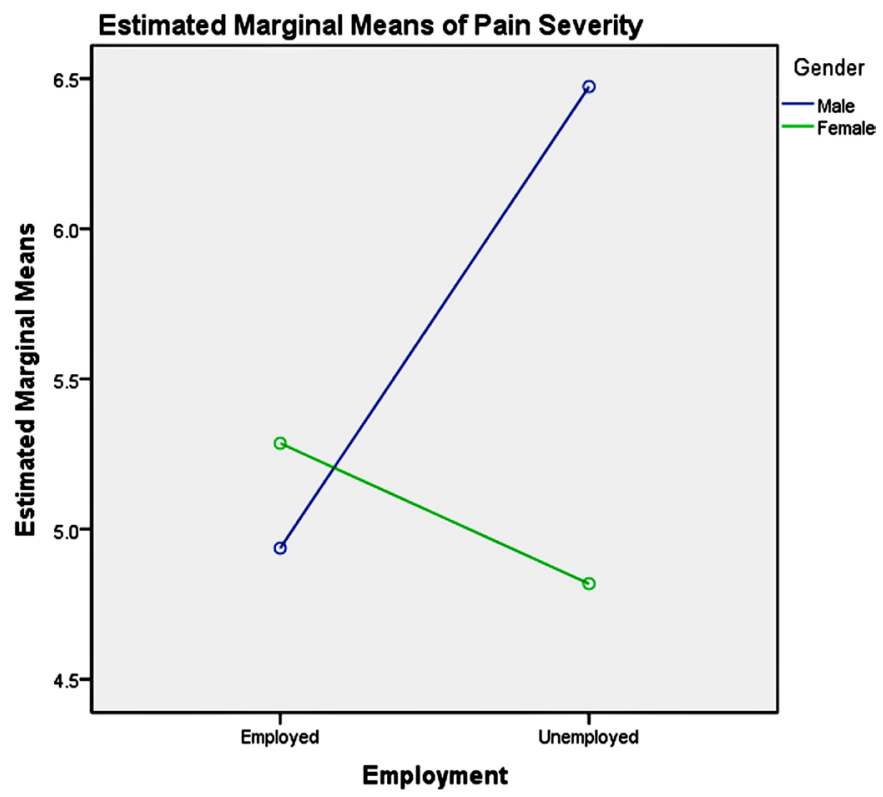

Figure 10 Gender-employment effects on pain severity in the elderly.
Table 15 Pairwise comparisons, middle-aged groupdepression

\begin{tabular}{llllll}
\multicolumn{6}{l}{ Dependent variable: pain severity } \\
Depression & $\begin{array}{l}\text { (I) } \\
\text { Gender }\end{array}$ & $\begin{array}{l}\text { (J) } \\
\text { Gender }\end{array}$ & $\begin{array}{l}\text { Mean } \\
\text { difference }\end{array}$ & SE & Significance \\
\hline Severe & 1 & 2 & $-^{*}$ & - & - \\
Moderate & 1 & 2 & -0.57 & 0.98 & 0.56 \\
Slight & 1 & 2 & 0.63 & 0.64 & 0.33 \\
None & 1 & 2 & 0.12 & 0.47 & 0.81 \\
\hline
\end{tabular}

Based on estimated marginal means.

Note: simple effect analysis of gender and depression symptoms of middle-aged group.

\section{Risk factors of experiencing pain}

Being female, older age, reported depression symptoms and medium-quality sleep were found to be risk factors for experiencing pain. In this study, women were more likely to report experiencing pain, which is in agreement with the majority of reported studies. $3133972-81$ From social psychology and culture psychology perspectives, most men have internalised a pressure to invoke stereotypical masculine behaviours to maintain a sense of power and control when they encounter actual or perceived threats to their masculine status. ${ }^{82-84}$ Therefore, they may under-report their pain experiences when compared with women. Older participants were also more likely to experience pain, which may be due to their worse physical condition $^{85}$ than younger participants. The result suggested that more attention should be focused on the treatment of pain in the elderly. Depressive symptoms were also a risk factor for experiencing pain, which is consistent with previous studies ${ }^{86} 87$ and suggests that more focus should be given to rural Chinese with depression symptoms. Medium-quality sleep improved the risk of experiencing pain, which suggests having sufficient and efficient sleep would be helpful of decreasing the risk of experiencing pain.

\section{Factors related to pain severity across ages and genders}

In this study, physical health and social health significantly impacted pain severity among the general population in rural China. Physical health significantly influenced pain intensity, which is in agreement with previous studies ${ }^{188} 89$ and common sense. The predictive role of social health on pain severity has not attracted attention by clinicians

Table 16 Pairwise comparisons, middle-aged group-Phealth

\begin{tabular}{|c|c|c|c|c|c|}
\hline \multicolumn{6}{|c|}{ Dependent variable: pain severity } \\
\hline P-health & $\begin{array}{l}\text { (I) } \\
\text { Gender }\end{array}$ & $\begin{array}{l}\text { (J) } \\
\text { Gender }\end{array}$ & $\begin{array}{l}\text { Mean } \\
\text { difference }\end{array}$ & SE & Significance \\
\hline $57-113$ & 1 & 2 & -0.04 & 0.95 & 0.97 \\
\hline $114-170$ & 1 & 2 & 0.51 & 0.36 & 0.16 \\
\hline
\end{tabular}

Based on estimated marginal means.

Note: simple effect analysis of gender and physical health of middleaged group. 


$\begin{aligned} & \text { Table } 17 \\
& \text { perceived }\end{aligned}$ stress
\begin{tabular}{llllll}
\multicolumn{4}{l}{ Pependent variable: pain severity } \\
\hline $\begin{array}{l}\text { Perceived } \\
\text { stress }\end{array}$ & $\begin{array}{l}\text { (I) } \\
\text { Gender }\end{array}$ & $\begin{array}{l}\text { (J) } \\
\text { Gender }\end{array}$ & $\begin{array}{l}\text { Mean } \\
\text { difference }\end{array}$ & SE & Significance \\
\hline $10-22$ & 1 & 2 & 0.30 & 0.48 & 0.53 \\
\hline $23-37$ & 1 & 2 & 0.07 & 0.54 & 0.91 \\
$38-50$ & 1 & 2 & 3.00 & 2.75 & 0.28 \\
\hline
\end{tabular}

Based on estimated marginal means.

Note: simple effect analysis of gender and perceived stress of middle-aged group.

and scholars. In this study, social health referred to social ties and social support. The findings presented here indicated that enlarging social networks and improving social support could be an effective social approach to decreasing pain severity in adults.

There are significant interactions between age, gender and employment status, depression symptoms, physical health and perceived stress. The simple test effects indicated that unemployed male participants experienced more intense pain across all age groups, compared with women. Men are encouraged by culture and society to take economic responsibility to feed their families and to participate in social competition to gain success, which may result in more intense psychological pain for men when they are unemployed. Thus, having stable employment is important for decreasing men's pain severity. Providing multiple job skills training to enhance men's employability across all age groups and offering more employment information and opportunities for them may be a useful social approach to mitigate the severity of their mental pain and psychoache from unemployment. Average-level stress increased young men's pain severity more dramatically than women's. High-level stress could increase middle-aged men's pain severity significantly compared with women's. Reducing perceived stress may be helpful for the pain management and treatment of men, which could be achieved by reducing-stress therapy. ${ }^{90}$

It has been reported that depression symptoms influenced pain experienced. ${ }^{86} 91-93$ Our study revealed that female adults' pain severity was much more entangled with depression symptoms in real-life situation. The absence of depression significantly decreased the pain severity in the young women, and severe depression symptoms significantly increased the pain severity in the middle-aged women. Treatment for depression symptoms may be effective for decreasing female's pain severity, which could be achieved using medication or psychotherapy (such as cognitive- behavioural therapy ${ }^{94}$ ), or complementary therapy such as exercises or meditation. Good physical health condition could significantly decrease young women's pain severity. For young women, improving their physical functioning could be a viable method for decreasing pain severity. This could be achieved by way of sports and exercise.
The factors related to pain severity differed across ages and genders, and therefore the treatment of pain across the general population should be designed with consideration for different ages and genders. Whether clinical pain treatments and analgesics should be customised for different genders and ages needs to be further explored.

\section{Strengths and limitations}

This study reported a 4-week prevalence of pain in rural China and the risk factors of experiencing pain of a rural Chinese sample. To our knowledge, this is the first study to explore the psychosocial and health condition predictors on pain severity and the interactions of gender and age with those variables in real-life situations. However, the study has a few limitations. First, our measurements of pain were not precise: we did not detail the site of pain, nor did we distinguish chronic pain from acute pain or physical pain from psychological pain. And the frequency of the pain experienced was not included in the study design, so how often the study subjects had experienced pain over the 4 weeks preceding the survey was not determined. Subjects could have experienced pain as frequently as every day or as rarely as just once in the span of 4 weeks. In future research, more detailed information (eg, pain duration, the frequency of pain and the pain sites) would be useful to refine the understanding of the various dimensions of pain. Another limitation is the cross-sectional design of the study, which precludes the induction of cause and effect and a potential causal relationship between independent variables and pain severity is inferred. In addition, the sample size only reflected the rural population of Liuyang, Hunan province and the findings of this study cannot be generalised to other rural counties in China. Future multicentres research is required to reflect the pain conditions of the rural population in China.

\section{CONCLUSIONS}

In conclusion, our study revealed that about two-thirds of adults in a rural Chinese sample experience pain over the course of 4 weeks and the predictors of pain severity differ significantly across ages and genders. Improving physical and social health could be effective in reducing the severity of pain, and the treatment of pain should be designed specifically for different ages and genders.

Acknowledgements The authors thank the local guides for guiding them to visit each household in the rural areas of Liuyang, Hunan province, China.

Contributors XKL, SYX, LZ, MH and HML contributed to the article. SYX and LZ designed the cross-sectional survey. MH and HML contributed to data collection. XKL drafted the manuscript conducting data analyses and SYX gave guidance on the paper. All the authors gave final approval to the version submitted for publication.

Funding The study was funded by the National Science and Technology Support Program, China (No 2009BAl77B01; No 2009BAl77B08) and the China Medical Board (CMB No 14-188).

Competing interests None declared.

Patient consent Not required. 
Ethics approval The ethics approval was obtained from the Institutional Review Board of the School of Public Health, Central South University (No CSU-GW-2010-01).

Provenance and peer review Not commissioned; externally peer reviewed.

Data sharing statement Extra data are available from the corresponding author on reasonable request.

Open access This is an open access article distributed in accordance with the Creative Commons Attribution Non Commercial (CC BY-NC 4.0) license, which permits others to distribute, remix, adapt, build upon this work non-commercially, and license their derivative works on different terms, provided the original work is properly cited and the use is non-commercial. See: http://creativecommons.org/ licenses/by-nc/4.0/

(C) Article author(s) (or their employer(s) unless otherwise stated in the text of the article) 2018. All rights reserved. No commercial use is permitted unless otherwise expressly granted.

\section{REFERENCES}

1. Gatchel RJ, Peng YB, Peters ML, et al. The biopsychosocial approach to chronic pain: scientific advances and future directions. Psychol Bull 2007;133:581-624.

2. Goldberg DS, McGee SJ. Pain as a global public health priority. BMC Public Health 2011;11:1471-2458.

3. Johannes CB, Le TK, Zhou X, et al. The prevalence of chronic pain in United States adults: results of an Internet-based survey. J Pain 2010;11:1230-9.

4. Riskowski JL. Associations of socioeconomic position and pain prevalence in the United States: findings from the national health and nutrition examination survey. Pain Med 2014;15:1508-21.

5. Taneja I, So S, Stewart JM, et al. Prevalence and severity of symptoms in a sample of African Americans and white participants. $J$ Cult Divers 2015;22:50-8.

6. Mansfield KE, Sim J, Jordan JL, et al. A systematic review and metaanalysis of the prevalence of chronic widespread pain in the general population. Pain 2016;157:55-64.

7. Nahin RL. Estimates of pain prevalence and severity in adults: United States, 2012. J Pain 2015;16:769-80.

8. Schopflocher D, Taenzer P, Jovey R. The prevalence of chronic pain in Canada. Pain Res Manag 2011;16:445-50.

9. Van Den Kerkhof EG, Hopman WM, Towheed TE, et al. The impact of sampling and measurement on the prevalence of self-reported pain in Canada. Pain Res Manag 2003;8:157-63.

10. Moulin DE, Clark AJ, Speechley M, et al. Chronic pain in Canadaprevalence, treatment, impact and the role of opioid analgesia. Pain Res Manag 2002;7:179-84.

11. Currow DC, Agar M, Plummer JL, et al. Chronic pain in South Australia-population levels that interfere extremely with activities of daily living. Aust N Z J Public Health 2010;34:232-9.

12. Chen J, Devine A, Dick IM, et al. Prevalence of lower extremity pain and its association with functionality and quality of life in elderly women in Australia. J Rheumatol 2003;30:2689-93.

13. Blyth FM, March LM, Brnabic AJ, et al. Chronic pain in Australia: a prevalence study. Pain 2001;89:127-34.

14. Fayaz A, Croft P, Langford RM, et al. Prevalence of chronic pain in the UK: a systematic review and meta-analysis of population studies. BMJ Open 2016;6:e010364.

15. Breivik H, Collett B, Ventafridda V, et al. Survey of chronic pain in Europe: prevalence, impact on daily life, and treatment. Eur J Pain 2006;10:287-333.

16. Branco JC, Bannwarth B, Failde I, et al. Prevalence of fibromyalgia: a survey in five European countries. Semin Arthritis Rheum 2010;39:448-53.

17. Langley PC. The prevalence, correlates and treatment of pain in the European Union. Curr Med Res Opin 2011;27:463-80.

18. Macfarlane GJ, Pye SR, Finn JD, et al. Investigating the determinants of international differences in the prevalence of chronic widespread pain: evidence from the European male ageing study. Ann Rheum Dis 2009;68:690-5.

19. Jackson $\mathrm{T}$, Chen $\mathrm{H}$, lezzi T, et al. Prevalence and correlates of chronic pain in a random population study of adults in Chongqing, China. Clin J Pain 2014;30:346-52.

20. Chen B, Li L, Donovan C, et al. Prevalence and characteristics of chronic body pain in China: a national study. Springerplus 2016;5:938.

21. Molero-Simarro R. Inequality in China revisited. The effect of functional distribution of income on urban top incomes, the urban- rural gap and the gini index, 1978-2015. China Economic Review 2017;42:101-17.

22. Xu H, Zhang W, Gu L, et al. Aging village doctors in five counties in rural China: situation and implications. Hum Resour Health 2014;12:36.

23. Zhou XD, Li L, Hesketh T. Health system reform in rural China: voices of healthworkers and service-users. Soc Sci Med 2014;117:134-41.

24. Macfarlane GJ. The epidemiology of chronic pain. Pain 2016;157:2158-9.

25. Coggon D, Ntani G, Palmer KT, et al. Patterns of multisite pain and associations with risk factors. Pain 2013;154:1769-77.

26. Sivertsen B, Petrie KJ, Skogen JC, et al. Insomnia before and after childbirth: The risk of developing postpartum pain-a longitudinal population-based study. Eur J Obstet Gynecol Reprod Biol 2017:210:348-54.

27. Mork PJ, Nilsen TI. Sleep problems and risk of fibromyalgia: longitudinal data on an adult female population in Norway. Arthritis Rheum 2012;64:281-4.

28. Boardman HF, Thomas E, Millson DS, et al. The natural history of headache: predictors of onset and recovery. Cephalalgia 2006;26:1080-8.

29. Odegård SS, Sand T, Engstrøm M, et al. The long-term effect of insomnia on primary headaches: a prospective population-based cohort study (HUNT-2 and HUNT-3). Headache 2011;51:570-80.

30. Choy EH. The role of sleep in pain and fibromyalgia. Nat Rev Rheumatol 2015;11:513-20.

31. Lerman SF, Rudich Z, Brill S, et al. Longitudinal associations between depression, anxiety, pain, and pain-related disability in chronic pain patients. Psychosom Med 2015;77:333-41.

32. Nordgren LF, Banas K, MacDonald G. Empathy gaps for social pain: why people underestimate the pain of social suffering. J Pers Soc Psychol 2011;100:120-8.

33. White RS, Jiang J, Hall CB, et al. Higher perceived stress scale scores are associated with higher pain intensity and pain interference levels in older adults. J Am Geriatr Soc 2014;62:2350-6.

34. Turk DC, Okifuji A. Psychological factors in chronic pain: evolution and revolution. J Consult Clin Psychol 2002;70:678-90.

35. Jackson $T$, Wang $Y$, Wang $Y$, et al. Self-efficacy and chronic pain outcomes: a meta-analytic review. J Pain 2014;15:800-14.

36. Racine M, Castarlenas $\mathrm{E}$, de la Vega $\mathrm{R}$, et al. Sex differences in psychological response to pain in patients with fibromyalgia syndrome. Clin J Pain 2015;31:425-32.

37. Thomas E, Peat G, Harris L, et al. The prevalence of pain and pain interference in a general population of older adults: crosssectional findings from the North Staffordshire Osteoarthritis Project (NorStOP). Pain 2004;110:361-8.

38. Wong WS, Fielding R. Prevalence and characteristics of chronic pain in the general population of Hong Kong. J Pain 2011;12:236-45.

39. Fillingim RB, King CD, Ribeiro-Dasilva MC, et al. Sex, gender, and pain: a review of recent clinical and experimental findings. J Pain 2009:10:447-85.

40. Myers CD, Tsao JC, Glover DA, et al. Sex, gender, and age: contributions to laboratory pain responding in children and adolescents. J Pain 2006;7:556-64.

41. Robinson ME, Riley JL, Myers CD, et al. Gender role expectations of pain: relationship to sex differences in pain. J Pain 2001;2:251-7.

42. Baidu. Liuyang. 2017 http://baike.baidu.com/link? url=sGeotSfR1sfK tjAmcZ0×5Lx34TN wS3icZTPOSkY5UsgTYjxOpx1×2aFFk9B-IKGJ CXmKn3XzOSc5KW0oonJRb5ox9lqxlyNzyP5MEylmO3

43. Wikepedia. Liuyang. 2017 https://en.wikipedia.org/wiki/Liuyang

44. Wikepedia. Hukou system. 2018 https://en.wikipedia.org/wiki/ Hukou_system

45. Myles PS, Troedel S, Boquest M, et al. The pain visual analog scale: is it linear or nonlinear? Anesth Analg 1999;89:1517.

46. Phan NQ, Blome C, Fritz F, et al. Assessment of pruritus intensity: prospective study on validity and reliability of the visual analogue scale, numerical rating scale and verbal rating scale in 471 patients with chronic pruritus. Acta Derm Venereol 2012;92:502-7.

47. Price DD, McGrath PA, Rafii A, et al. The validation of visual analogue scales as ratio scale measures for chronic and experimental pain. Pain 1983; 17:45-56.

48. Dimitriadis Z, Strimpakos N, Kapreli E, et al. Validity of visual analog scales for assessing psychological states in patients with chronic neck pain. J Musculoskelet Pain 2014;22:242-6.

49. Appukuttan D, Vinayagavel M, Tadepalli A. Utility and validity of a single-item visual analog scale for measuring dental anxiety in clinical practice. J Oral Sci 2014;56:151-6.

50. Perrot S, Rozenberg S, Moyse D, et al. Comparison of daily, weekly or monthly pain assessments in hip and knee osteoarthritis. A 29-day prospective study. Joint Bone Spine 2011;78:510-5. 
51. Jamison RN, Raymond SA, Slawsby EA, et al. Pain assessment in patients with low back pain: comparison of weekly recall and momentary electronic data. J Pain 2006;7:192-9.

52. Mendoza TR, Dueck AC, Bennett AV, et al. Evaluation of different recall periods for the US national cancer institute's PRO-CTCAE. Clin Trials 2017;14:255-63.

53. Stull DE, Leidy NK, Parasuraman B, et al. Optimal recall periods for patient-reported outcomes: challenges and potential solutions. Curr Med Res Opin 2009;25:929-42.

54. Rasmussen CDN, Holtermann A, Jørgensen MB. Recall bias in low back pain among workers: effects of recall period and individual and work-related factors. Spine 2017.

55. Jun X, Binhui W, Minyan H. The develoment and evaluation of selfrated health measurement scale-prior test version. Chinese Journal of Behavioral Medical Science 2000;9:65-8.

56. Xu J, Tan J, Wang Y, et al. Evaluation of the self-rated health measurement scale-the revised version 1.0. Chinese Mental Health Journal 2003;17:301-5.

57. Xu J, Xie Y, Li B, et al. The study of validity on self-rated health measurement scale-the revised version 1.0. Chinese Journal of Clinical Rehabilitation 2002;6:2082-5.

58. Fried El, Nesse RM, Zivin K, et al. Depression is more than the sum score of its parts: individual DSM symptoms have different risk factors. Psychol Med 2014;44:2067-76.

59. Zimmerman M. Symptom severity and guideline-based treatment recommendations for depressed patients: implications of DSM-5's potential recommendation of the PHQ-9 as the measure of choice for depression severity. Psychother Psychosom 2012;81:329-32.

60. Chen TM, Huang FY, Chang C, et al. Using the PHQ-9 for depression screening and treatment monitoring for Chinese Americans in primary care. Psychiatr Serv 2006;57:976-81.

61. Wang W, Bian Q, Zhao Y, et al. Reliability and validity of the Chinese version of the Patient Health Questionnaire (PHQ-9) in the general population. Gen Hosp Psychiatry 2014;36:539-44.

62. Spitzer RL, Kroenke K, Williams JB, et al. A brief measure for assessing generalized anxiety disorder: the GAD-7. Arch Intern Med 2006;166:1092-7.

63. Löwe B, Decker O, Müller S, et al. Validation and standardization of the Generalized Anxiety Disorder Screener (GAD-7) in the general population. Med Care 2008;46:266-74.

64. Beard C, Björgvinsson T. Beyond generalized anxiety disorder: psychometric properties of the GAD-7 in a heterogeneous psychiatric sample. J Anxiety Disord 2014;28:547-52.

65. Franckowiak BA, Glick DF. The effect of self-efficacy on treatment. $J$ Addict Nurs 2015;26:62-70.

66. Luszczynska A, Scholz U, Schwarzer R. The general self-efficacy scale: multicultural validation studies. J Psychol 2005;139:439-57.

67. Leung DY, Leung AY. Factor structure and gender invariance of the Chinese general self-efficacy scale among soon-to-be-aged adults. J Adv Nurs 2011;67:1383-92.

68. Cohen S, Kamarck T, Mermelstein R. A global measure of perceived stress. J Health Soc Behav 1983;24:385-96.

69. Chaaya M, Osman H, Naassan G, et al. Validation of the Arabic version of the cohen perceived stress scale (PSS-10) among pregnant and postpartum women. BMC Psychiatry 2010;10:1471-1244.

70. $\mathrm{Ng} \mathrm{SM}$. Validation of the 10 -item Chinese perceived stress scale in elderly service workers: one-factor versus two-factor structure. BMC Psychol 2013;1:9.

71. WHO. World health day 2012 - Ageing and health. Geneva: WHO, 2012.

72. Hashmi JA, Davis KD. Deconstructing sex differences in pain sensitivity. Pain 2014;155:10-13.
73. Hardt J, Jacobsen C, Goldberg J, et al. Prevalence of chronic pain in a representative sample in the United States. Pain Med 2008;9:803-12

74. Maia Costa Cabral D, Sawaya Botelho Bracher E, Dylese Prescatan Depintor J, et al. Chronic pain prevalence and associated factors in a segment of the population of São Paulo City. J Pain 2014;15:1081-91.

75. Cho NH, Jung YO, Lim SH, et al. The prevalence and risk factors of low back pain in rural community residents of Korea. Spine 2012;37:2001-10.

76. Jackson T, Thomas S, Stabile V, et al. Prevalence of chronic pain in low-income and middle-income countries: a systematic review and meta-analysis. Lancet 2015;385(Suppl 2):S10.

77. Schneider S, Randoll D, Buchner M. Why do women have back pain more than men? A representative prevalence study in the federal republic of Germany. Clin J Pain 2006;22:738-47.

78. Son KM, Cho NH, Lim SH, et al. Prevalence and risk factor of neck pain in elderly Korean community residents. J Korean Med Sci 2013;28:680-6.

79. Mapplebeck JC, Beggs S, Salter MW. Sex differences in pain: a tale of two immune cells. Pain 2016;157(Suppl 1):S2-6.

80. Bouhassira D, Lantéri-Minet M, Attal N, et al. Prevalence of chronic pain with neuropathic characteristics in the general population. Pain 2008;136:380-7.

81. Torrance N, Smith BH, Bennett MI, et al. The epidemiology of chronic pain of predominantly neuropathic origin. Results from a general population survey. J Pain 2006;7:281-9.

82. Berke DS, Reidy DE, Miller JD, et al. Take it like a man: genderthreatened men's experience of gender role discrepancy, emotion activation, and pain tolerance. Psychol Men Masc 2016;18:62-9.

83. Moore TM, Stuart GL. A review of the literature on masculinity and partner violence. Psychol Men Masc 2005;6:46-61.

84. Vandello JA, Bosson JK. Hard won and easily lost: a review and synthesis of theory and research on precarious manhood. Psychol Men Masc 2013;14:101-13.

85. Landmark BT, Gran SV, Kim HS. Pain and persistent pain in nursing home residents in Norway. Res Gerontol Nurs 2013;6:47-56.

86. Han C, Pae CU. Pain and depression: a neurobiological perspective of their relationship. Psychiatry Investig 2015;12:1-8.

87. Wiech K, Tracey I. The influence of negative emotions on pain: behavioral effects and neural mechanisms. Neuroimage 2009;47:987-94.

88. Parreira PC, Maher CG, Latimer J, et al. Can patients identify what triggers their back pain? Secondary analysis of a case-crossover study. Pain 2015;156:1913-9.

89. Bernfort L, Gerdle B, Rahmqvist M, et al. Severity of chronic pain in an elderly population in Sweden-impact on costs and quality of life. Pain 2015;156:521-7.

90. Johnson AC, Greenwood-Van Meerveld B. Stress-induced pain: a target for the development of novel therapeutics. J Pharmacol Exp Ther 2014;351:327-35.

91. Keefe FJ, Wilkins RH, Cook WA, et al. Depression, pain, and pain behavior. J Consult Clin Psychol 1986;54:665-9.

92. Li JX. Pain and depression comorbidity: a preclinical perspective. Behav Brain Res 2015;276:92-8.

93. Pinheiro MB, Ferreira ML, Refshauge K, et al. Genetics and the environment affect the relationship between depression and low back pain: a co-twin control study of Spanish twins. Pain 2015;156:496-503.

94. Burns JW, Nielson WR, Jensen MP, et al. Specific and general therapeutic mechanisms in cognitive behavioral treatment of chronic pain. J Consult Clin Psychol 2015;83:1-11. 